\title{
Avaliação qualitativa e quantitativa dos impactos ambientais na zona urbana do igarapé Altamira, Altamira, Pará, Brasil
}

Qualitative and quantitative assessment of environmental impacts in the urban area of the Altamira creek, Altamira, Pará, Brazil

Evaluación cualitativa y cuantitativa de los impactos ambientales en el área urbana del arroyo Altamira, Altamira, Pará, Brasil

\section{Resumo}

O igarapé Altamira, um dos três componentes da sub-bacia do Rio Xingu, no oeste do Pará, foi alvo de intensa degradação devido à ocupação irregular em ambas as margens da zona urbana desse munícipio. A Norte Energia S/A, realocou a população e iniciou a recuperação ambiental desse corpo hídrico, com o intuito de transformar o local em uma Unidade de Conservação após o término da recuperação. O objetivo dessa pesquisa foi avaliar qualitativamente e quantitativamente, os impactos no ambiente e comunidades, antes e após a intervenção da empresa responsável pela UHE Belo Monte, as alterações positivas e negativas dessas transformações e comparar os dois cenários. O método empregado foi o observativo, sistemático, direto, in situ, construção de memorial fotográfico, e a confecção de duas Matrizes de Leopold adaptadas, para identificação e avaliação delas. Osa dados obtidos e analisados indicaram que: (1) a recuperação ambiental se caracterizou como positiva; (2) ainda ocorrem impactos negativos no local, os quais foram atenuados. Conclui-se que, a situação inicial foi mitigada, mas os impactos negativos ainda ocorrentes devem ser sanados com o término da obra e alcançar e meta estabelecida pela empresa em tela.

Palavras-chave: Ocupação irregular; Matriz de impacto; Unidade de conservação.

\begin{abstract}
The Altamira creek, one of the three components of the Xingu River sub-basin, in western Pará, was subject to intense degradation due to irregular occupation on both banks of the urban area of this municipality. North Energy S/A, relocated the population and started the environmental recovery of this water body, with the intention of transforming the site into a Conservation Unit after the recovery is completed. The objective of this research was to evaluate qualitatively and quantitatively, the impacts on the environment and communities before and after the intervention of the company responsible for the Belo Monte HPP, the positive and negative changes of these transformations and to compare the two scenarios. The method used was observational, systematic, direct, in situ, photographic memorial construction, and the making of two Leopold Matrices adapted for their identification and evaluation. The data obtained and analyzed indicated that (1) environmental recovery was characterized as positive; (2) negative impacts still occur at the site, which have been mitigated. We conclude that the initial situation was mitigated, but the negative impacts still occurring must be resolved with the completion of the work and achieve the goal set by the company.
\end{abstract}

Keywords: Irregular occupation; Impact matrix; Conservation unit.

\section{Resumen}

El arroyo Altamira, uno de los tres componentes de la subcuenca del río Xingu, en el oeste de Pará, fue sometido a una intensa degradación debido a la ocupación irregular en ambas márgenes del área urbana de este municipio. La Energía del Norte S/A, reubicó a la población e inició la recuperación ambiental de este cuerpo de agua, con el objetivo de transformar el sitio en una Unidad de Conservación tras el fin de la recuperación. El objetivo de esta investigación fue evaluar cualitativa y cuantitativamente los impactos en el medio ambiente y en las comunidades antes y después de la intervención de la empresa responsable de la CHE de Belo Monte, los cambios positivos y negativos de estas transformaciones y comparar los dos escenarios. El método utilizado fue observacional, 
sistemático, directo, in situ, de construcción de monumentos fotográficos, y la realización de dos matrices de Leopold adaptadas para su identificación y evaluación. Los datos obtenidos y analizados indicaron que: (1) la recuperación del medio ambiente se caracterizó como positiva; (2) todavía se producen impactos negativos en el lugar, que fueron atenuados. Se concluye que la situación inicial fue mitigada, pero los impactos negativos que aún se producen deben ser remediados con la finalización de la obra y lograr el objetivo fijado por la empresa en cuestión.

Palabras clave: Ocupación irregular; Matriz de impacto; Unidad de conservación.

\section{Introdução}

Nos últimos 30 anos, a sociedade brasileira tornou-se mais urbanizada e provocou um contesto urbanístico que se evidencia como uma ruptura ambiental já que ocupa espaços onde havia floresta, rios, igarapés, dentre outros ambientes naturais. Além dessa configuração moderna, nota-se que o território não acompanhou o ritmo urbanístico imposto por ela e, com isso, as áreas de conceitos naturais estão modificadas e habitat (Brito \& Pinho, 2012).

Porém, é necessário observar que, a ocupação no Brasil sempre foi caracterizada sem qualquer planejamento. A consequência disso foi a destruição dos recursos naturais, em particular, córregos e florestas, essa ocupação causa um crescimento desordenado de domicílios urbanos em áreas que deveriam ser preservadas para manter o equilíbrio ecológico e hidrológico de uma Microbacia (Santana, 2011).

Acerca da ausência de um planejamento e ordenamento para o espaço urbano, o município de Altamira, teve origem às margens do rio Xingu (Silva et al., 2020), e outros corpos hídricos (Ex.: Igarapé Panelas) componentes da rede hidrográfica desse local. Nesse contexto, a ocupação territorial dessa localidade, concentrou-se às margens dele, em 1880. A partir deste local, os freis italianos capuchinhos, utilizaram a mão-de-obra indígena, para o povoamento local entre os igarapés Ambé e Panelas, e transversalmente, apresenta o Igarapé Altamira (PMA, 2010).

A partir desse fato, a paisagem urbana foi desenhada em três zonas territoriais: (1) zona central, delimitada pela distância entre dois igarapés (Ex.: igarapé da Cachoeira Grande até o Igarapé Amazonas); (2) zona urbana, situada entre o Igarapé da Cachoeira Grande e o Igarapé do Velho Chico; (3) zona suburbana, compreendida entre os igarapés do Igarapé Cachoeira Grande e do Igarapé da Cachoeirinha (Pinto, 2008).

Em função desse crescimento desordenado nas cidades, e ocupação das margens dos igarapés, são causados diversos impactos ao meio ambiente e a própria sociedade, cuja avaliação é efetuada por uma técnica denominada Avaliação de Impacto Ambiental (AIA) que é um instrumento de Política Ambiental (Lei n. ${ }^{\circ}$ 6.938/1981) que permite uma diagnose, quantificação e qualificação subjetivas, mas com eficácia e eficiência para prevenir, monitorar identificar as alterações ambientais de um determinado empreendimento (Farinaccio \& Tessler, 2010).

O documento político ambiental também norteia a elaboração de documentos mais específicos aos empreendimentos como, por exemplo, usinas hidrelétricas, então denominado Projeto Básico Ambiental (PBA). Com ele, faz-se um detalhamento que permite identificar quais serão as medidas (controle, recuperação, regeneração, reabilitação, estimulação) cabíveis em casos de desequilíbrio ambiental e que devem constar nos Estudos de Impactos Ambientais, de forma clara, técnica e concisa (Brasil, 2002; Rush \& Krull, 2017).

Dentre essas medidas, está à recuperação de margens dos corpos hídricos, a criação de uma Unidade de Conservação no local, com objetivo de organizar o novo espaço urbano a partir da desocupação dessas margens ou de outras áreas que sejam úteis a empreendimento, isso em função das significâncias dos impactos que poderão ser causados pela implantação e operação do empreendimento (Ramos et al., 2017). Portanto, o objetivo dessa pesquisa foi a avaliação qualitativa e quantitativa da situação ambiental do Igarapé Altamira antes e após a recuperação ambiental do local, bem como a identificação dos ganhos ambientais e possíveis adversidades do projeto relacionadas a população, e comparação desses cenários. 


\section{Material e métodos}

\section{1 Área de estudo}

O Município de Altamira está localizado na região Oeste do estado do Pará, a 754 km da capital Belém e apresenta

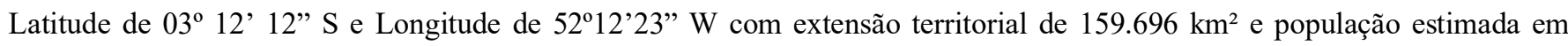
108.382 habitantes. Quanto a hidrografia, ela é constituída pelo Rio Xingu e um de seus afluentes, o Rio Iriri. Estes dois rios formam uma configuração alongada em forma de um " $v$ " invertido e junto com seus inúmeros contribuintes que se distribuem por todo o território municipal (IBGE, 2015; PMA, 2010).

O clima nesse município, pela classificação de Köppen, é “Am” (parte norte) e "Aw”, com $\mathrm{T}_{\text {mín/ano }}=22,1^{\circ} \mathrm{C} ; \mathrm{T}_{\text {máxi/ano }}$ $=32,4{ }^{\circ} \mathrm{C}$, e precipitação pluviométrica média igual a $2.123 \mathrm{~mm} /$ ano Souza et al., 2013). Já a pedologia do município, é caracterizada por solos predominantemente do tipo Latossolo amarelo distrófico típico com Argilossolo vermelho distrófico. Por fim, a cobertura vegetal é denominada pela feição Floresta Ombrófila densa e aberta com árvores de médio e grande porte (IBGE, 2008).

Figura 1. Localização do Município de Altamira - Pará.

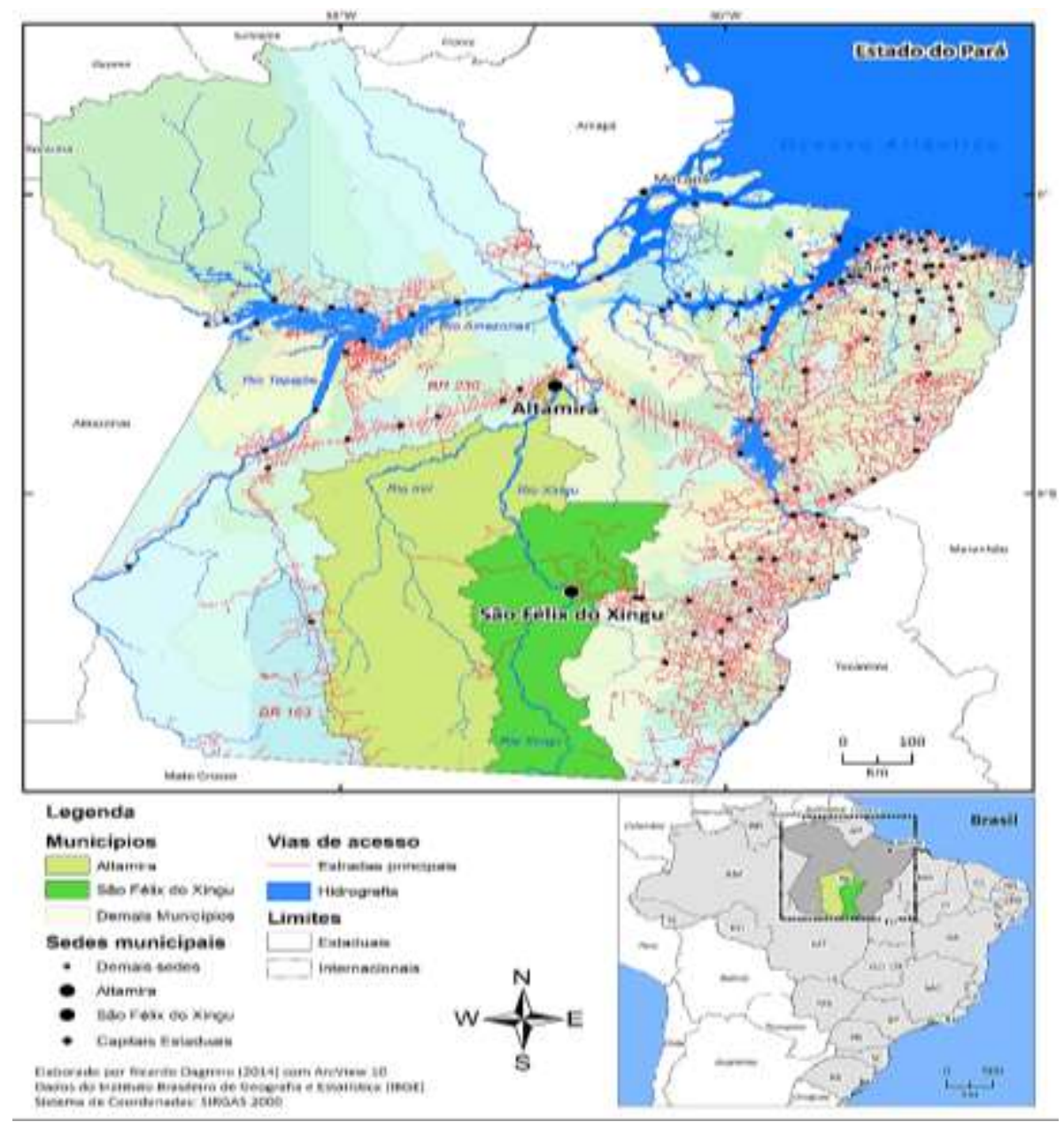

Fonte: Dagnino (2014).

De acordo com os dados históricos contidos no acervo da Câmara Municipal, em 1874, Altamira surge acoplado ao antão denominado Souzel (Criado pela Lei n. ${ }^{\circ}$ 811/1874) e, em 1911 (Lei Estadual n. ${ }^{\circ} 1234 / 1911$ ), ocorre a emancipação dele, eleva-se a condição de distrito, em 1912, já em passa a condição de município (Decreto Legislativo n. ${ }^{\circ}$ 1.234/1911) e, finalmente em 1917 (Lei estadual n. ${ }^{\circ}$ 1604/1917), a condição de cidade (IBGE, 2017; PMA, 2010). 
É necessário observar que na Área de Proteção Permanente (APP) do Igarapé Altamira, já ocorria presença de unidades residências e comerciais que, de forma direta, faziam uso do recurso hídrico disponível e causavam perda de qualidade ambiental dele. Foi dessa forma que esse corpo hídrico foi "urbanizado" (Vargas, 2008), e com maior intensidade entre 1980 e 2000 (Figura 2).

Figura 2. Vista superior da evolução urbana de Altamira com destaque no Igarapé Altamira - Pará.

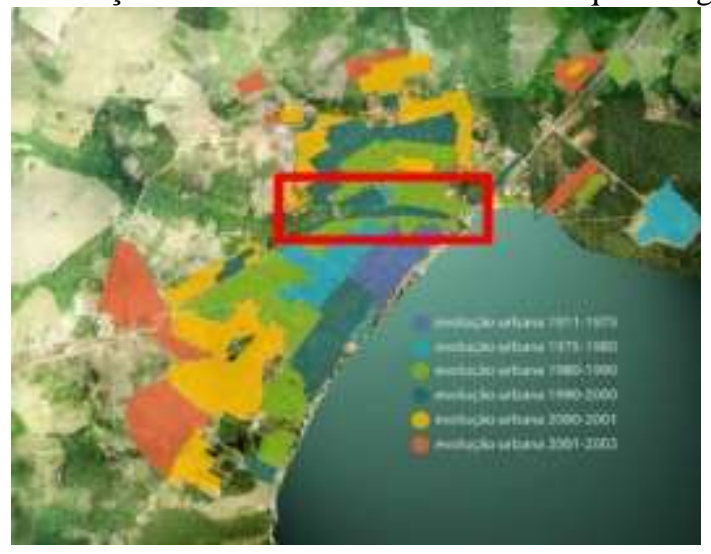

Fonte: PMA (2010).

Em função da liberação da licença de instalação da Usina Hidrelétrica (UHE) Belo Monte, em 2011, esse processo intensificou-se ainda mais devido a especulação imobiliária no local. Devido a importância ambiental, estas áreas deveriam estar sendo desocupadas progressivamente e recuperadas e os seus moradores reassentados em áreas apropriadas (Girelli, 2009).

\subsection{Local do estudo}

O corpo hídrico em análise o igarapé Altamira, de acordo com Lobato et al. (2017), é um dos constituintes do curso médio do rio Xingu, e compõe a sub-bacia desse rio juntamente com os igarapés Panelas e Ambé, que atravessam o perímetro urbano dessa cidade (Figura 3).

Figura 3. Sub-bacia do rio Xingu e os três igarapés que a constituem, dentre eles, o Igarapé Altamira, Altamira, Pará.
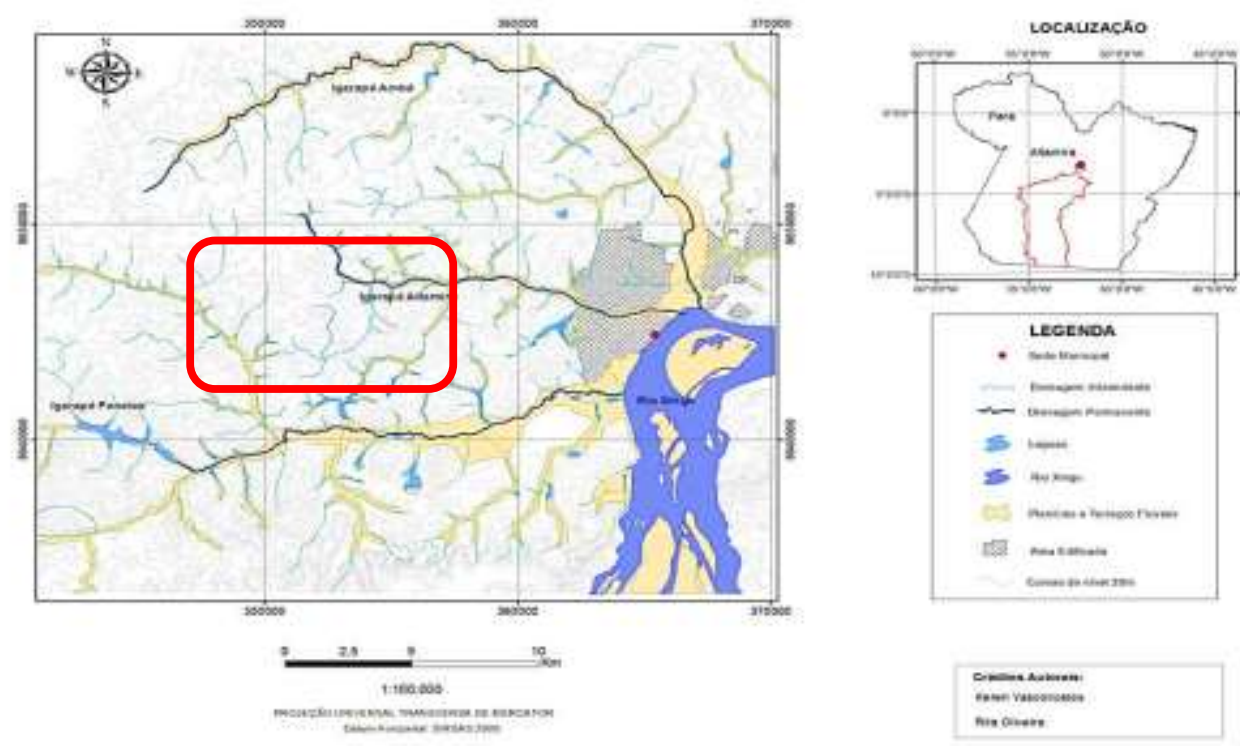

Fonte: Oliveira (2016). 
O igarapé Altamira, possui curso orientado geograficamente no sentido oeste-leste, tem seu traçado de jusante, com cerca de 1,3 km, a partir da foz, na zona urbana de Altamira. O ponto que delimita a área estudada é a Rua Gondim Lins. A intenção foi incluir apenas as áreas efetivamente urbanizadas, haja vista que as demais áreas marginais não possuíam uma ocupação consolidada (Figura 4).

Figura 4. Igarapé Altamira no perímetro urbano (em azul) onde ocorreram as ações da Norte Energia. Altamira - Pará.

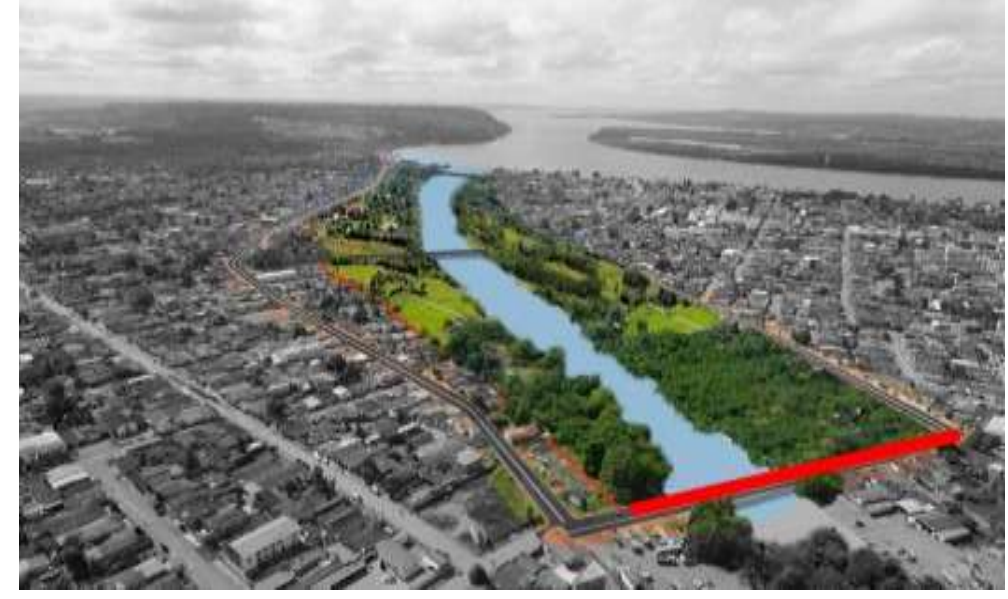

Fonte: Norte Energia (2016).

Nas décadas de 19 e 20, a cidade de Altamira, apresentou crescimento populacional exacerbado e desordenador. Em consequência disso a ocupação de áreas de APP, como as margens do igarapé Altamira promoveu um aglomerado de unidades arquitetônicas com as mais diversas funções, dentre elas destaca-se a submoradia e comercio tanto no varejo quanto no atacado, além de ofertas de serviços diversos (Eletrobrás, 2009). Isso provocou um desordenamento no espaço urbano além de provocar agravamento nas condições socioambientais (Neves et al., 2016).

\subsection{Método}

O método empregado nessa pesquisa, quanti-qualitativo, foi sintetizado por Pereira et al. (2018) como aquele que permite a interpretação e emissão de opiniões a partir da visão do pesquisador, além disso, esses autores afirmam que ele também permite a coleta de dados quantitativos ou numéricos, a partir de mensurações efetuadas como, por exemplo, grau de significância, porcentagens, dentre outros. Para obtenção dos dados primários, aplicou-se uma lista de verificação (Check list, inglês) que foi complementada a observação sistemática. Para melhor aplicá-la, dividiu-se a mesma em quatro etapas distintas:

(1) Levantamento de dados documentais (periódicos; links eletrônicos; livros; órgãos governamentais e empresa privada, com recorte temporal situado entre 2010 a 2021, excetuem-se desse período, as legislações e literaturas pioneiras sobre o tema da pesquisa. Foi dada prioridade a publicações entre 2016 a 2021, para obtenção de dados mais atualizados acerca desse assunto).

(2) 03 visitas ao local do estudo $(15.09 .2016$; 30.09.2016; 15.10.2016) para composição do memorial fotográfico. Coleta de dados com a aplicação de um Check list descritiva, sobre a situação -base;

(3) Alocação dos dados obtidos (sobre os impactos) em Matriz de Leopold adaptada para este tipo de avaliação (Quadros 1 e 2) nos meios físicos; biótico e socioeconômico para valoração de 1 a 10;

(4) Após a obtenção dos dados quantitativos, fez-se uso de planilhas eletrônicas contidas no software Excel, versão 2019 (Microsoft Corporation, 2019). Em seguida, elaboraram-se tabelas e gráficos de acordo com o preconizado pelo Instituto Brasileiro de Geografia e Estatística (IBGE, 1993). 


\subsection{Alocação dos dados obtidos}

Para a alocação dos dados obtidos foram adaptadas duas matrizes de interação de Leopold. A matriz 1 foi preenchida com os dados obtidos para a situação "antes da recuperação". Na matriz 2, foram inseridos os dados obtidos "após a recuperação. Para o correto preenchimento e aplicação dos critérios e conceitos (Quadro 1), empregaram-se aqueles utilizados por Amorim (2011) e Sanchez (2013).

Quadro 1. Critérios e conceitos utilizados para o preenchimento das Matrizes de Leopoldo 1 e 2.

\begin{tabular}{|c|c|c|c|}
\hline $\begin{array}{l}\text { CRITÉRIOS DE } \\
\text { IMPORTÂNCIA }\end{array}$ & T. I. & V. & DESCRIÇÃO \\
\hline \multirow{2}{*}{ EXPRESSÃO } & Positivo & 1 & Causa benefícios ao meio ambiente \\
\hline & Negativo & -1 & Causa adversidades ao meio ambiente \\
\hline \multirow{2}{*}{ ORIGEM } & Direto & 2 & $\begin{array}{l}\text { Decorrem das atividades ou ações realizadas pelo } \\
\text { empreendedor }\end{array}$ \\
\hline & Indireto & 1 & $\begin{array}{l}\text { Decorrem de um impacto direto causado pelo projeto } \\
\text { em análise }\end{array}$ \\
\hline \multirow{2}{*}{ DURAÇÃO } & Temporários & 1 & $\begin{array}{l}\text { Manifestam-se durante uma ou mais fases do projeto e } \\
\text { cessam quando termina essa fase }\end{array}$ \\
\hline & Permanente & 2 & $\begin{array}{l}\text { Representam uma alteração definitiva de um } \\
\text { componente do meio }\end{array}$ \\
\hline \multirow{2}{*}{ ESCALA TEMPORAL } & Imediato & 2 & $\begin{array}{l}\text { São aqueles que ocorrem simultaneamente à ação que o } \\
\text { gera }\end{array}$ \\
\hline & $\begin{array}{l}\text { Médio ou } \\
\text { Longo Praz }\end{array}$ & 1 & $\begin{array}{l}\text { São os que ocorrem com certa defasagem em relação à } \\
\text { ação que os geram }\end{array}$ \\
\hline \multirow[t]{2}{*}{ REVERSIBILIDADE } & Reversível & 1 & $\begin{array}{l}\text { O ambiente consegue retornar ao seu estado anterior } \\
\text { caso: cesse a solicitação externa, ou, seja implantada } \\
\text { uma ação corretiva }\end{array}$ \\
\hline & Irreversível & 2 & $\begin{array}{l}\mathrm{O} \text { ambiente afetado não consegue retornar ao seu } \\
\text { estado anterior }\end{array}$ \\
\hline \multirow[b]{2}{*}{ CUMULATIVIDADE } & Cumulativo & 2 & São aqueles que se acumulam no tempo e no espaço \\
\hline & $\begin{array}{l}\text { Não } \\
\text { cumulativos }\end{array}$ & 1 & Não se acumulam no tempo e no espaço \\
\hline \multirow{2}{*}{ ESCALA ESPACIAL } & Local & 1 & $\begin{array}{l}\text { A abrangência se restringe aos limites da área do } \\
\text { empreendimento }\end{array}$ \\
\hline & Regionais & 2 & $\begin{array}{l}\text { A Abrangência ultrapassa os limites do } \\
\text { empreendimento. }\end{array}$ \\
\hline
\end{tabular}

Legendas: T. I. Tipo de Impacto; V. valor aplicado. Fonte: Amorim (2011) e Sanchez (2013).

O cálculo para significância foi efetuado de acordo com o preconizado por Amorim (2011), com o uso da Equação 1. Ela é resultado da soma ponderada do valor atribuído a origem com a duração, escala temporal, reversibilidade, cumulatividade e escala espacial, multiplicada pela expressão do impacto.

$$
\text { Significância }=E \times\left(\sum O+D+E T+R+C+E E\right)
$$

Onde: $\mathbf{E}=$ Expressão $; \mathbf{O}=$ Origem $; \mathbf{D}=$ Duração $; \mathbf{E T}=$ Escala Temporal; $\mathbf{R}=$ Reversibilidade. $\mathbf{C}=$ Cumulatividade; $\mathbf{E E}=$ Escala Espacial 
Após obter o resultado da significância, esse número é classificado como pequeno, médio ou grande. Essa classificação é baseada nos valores máximos e mínimos que podem ser atingidos para cada impacto, conforme os valores estabelecidos para cada critério (Figura 5).

Figura 5. Classificação da significância dos impactos positivos e negativos.

\begin{tabular}{|c|c|c|c|c|c|c|c|}
\hline SIGNIFICÂNCIA POSITIVA & 6 & 7 & 8 & 9 & 10 & 11 & 12 \\
\hline CLASSIFICAÇÃO & \multicolumn{1}{|c|}{ PEQUENA } & \multicolumn{5}{|c|}{ MÉDIA } & \multicolumn{2}{|c|}{ GRANDE } \\
\hline \hline SIGNIFICÂNCIA NEGATIVA & -6 & -7 & -8 & -9 & -10 & -11 & -12 \\
\hline CLASSIFICAÇÃO & PEQUENA & \multicolumn{3}{|c|}{ MÉDIA } & \multicolumn{2}{|c|}{ GRANDE } \\
\hline
\end{tabular}

Fonte: Amorim (2011) e Sànchez (2013).

Por fim, os critérios e impactos ambientais identificados foram alocados em planilhas eletrônicas contidas no software Excel, versão 2019 (MICROSOFT CORPORATION, 2019). Em seguida, aplicou-se a estatística descritiva para o cálculo do valor médio da significância nos três meios analisados e do percentual de impactos.

\section{Resultados e Discussão}

\subsection{Situação da área antes da recuperação do igarapé Altamira}

Os dados obtidos e analisados indicaram que as residências até então existentes, eram palafitas simples. Em 2009, as margens do Igarapé Altamira (Figura 6a), habitavam 7.667 pessoas (Eletrobrás, 2009). Em relação, ao esgotamento sanitário, os dados analisados indicaram a inexistência dele, e em muitas residências, as instalações hidrossanitárias eram precárias (Figura 6b), dessa forma os dejetos eram eliminados diretamente no Igarapé, onde havia poços amazônicos (cacimbas) escavados à margem do corpo hídrico, para coleta e armazenamento de água destinada aos afazeres domésticos e higiene pessoal (Figura 6c).

Figura 6. a) Vista forntal do Igarapé Altamira; b) Vista posterior das Palafitas ao longo do Igarapé Altamira; c) coleta e armazenamento de água nas palafitas. Altamira - Pará.

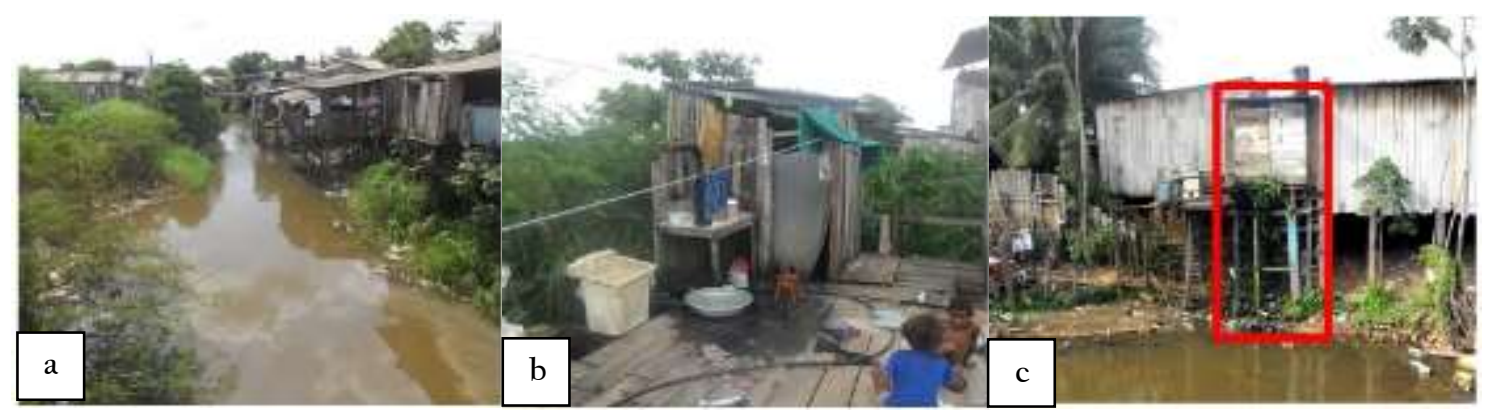

Fonte: Autores (2019).

A ausência de um planejamento urbano quanto a ocupação das margens do igarapé Altamira, é frequente no contexto amazônico devido a hipossuficiência econômica dessas comunidades e as origens dos municípios e cidades dessa região. Sobre esse tema, Freitas et al. (2016), realizaram pesquisa de campo no município de Vitória do Xingu - PA, e os dados obtidos por eles, indicaram que essas ocupações ocorrem devido a situação econômica em que se encontram as pessoas que ali residem. Todavia isso tem provocado perdas da estrutura ciliar, além de não possuírem nenhuma oferta de serviços básicos essenciais à qualidade de vida das comunidades que fixam residências nesses locais. 
Outro fator associado a este tipo de ocupação, foi objeto de pesquisa bibliográfica efetuada por Duarte et al. (2013). Os dados que eles obtiveram indicaram que, dentre tantas causas identificadas, duas delas, o crescimento populacional e o déficit habitacional. Ambas ocasionaram problemas ambientais como a poluição dos corpos hídricos já que essas populações se instalaram às margens deles. No histórico acerca da fundação da cidade Altamira, isso foi evidenciado.

Os dados também indicaram que nessa área havia um grande déficit na coleta pública de resíduos domiciliares, com isso, a comunidade do local, destinava os resíduos sólidos (Ex.: móveis usados, animais em decomposição, e medicamentos) por eles gerados, à parte anterior (7a), e posterior (7b), do igarapé Altamira.

Figura 7. a) resíduos sólidos domésticos depositados nas margens do Igarapé Altamira; b) Vista posterior das palafitas com acúmulo de resíduos sólidos domésticos.

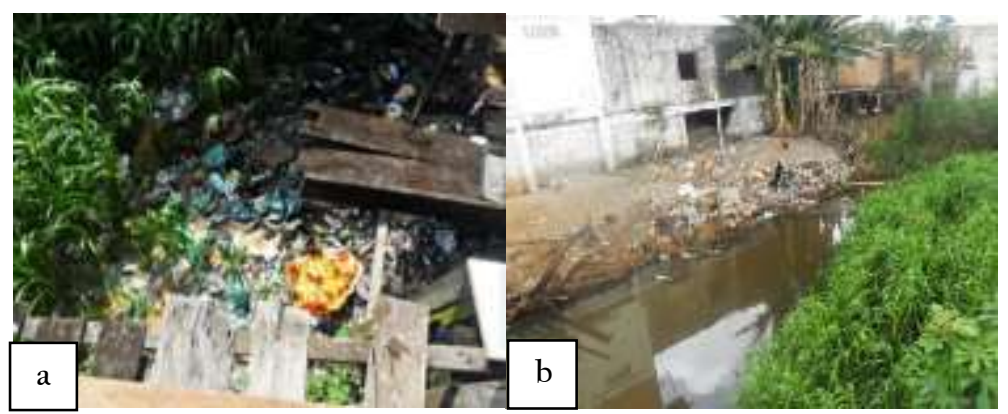

Fonte: Autores (2019).

$\mathrm{Na}$ informação cedida pela Eletronorte, havia 7.667 residentes nesse local, todavia, Mendes et al. (2020) afirmam que a média de habitantes era de 22.000 pessoas, logo a quantidade de resíduos sólidos gerados e dispostos em locais inadequados era elevado. Sobre os despejos irregulares de lixo, Luz et al. (2012) efetuaram estudos na cidade de Altamira - PA, e concluiram que, além das comunidades que habitam as margens do Igarapé Altamira, ocorre destino inadequado às margens desse corpo hídrico, e que durante o período chuvoso, são deslocados, pelo escoamento superficial para o interior dele. Nessa pesquisa, verificou-se que a comunidade se abastecia das águas desse igarapé, para higiene pessoal e uso no cotidiano dessas residências.

A análise dos dados obtidos pra a mobilidade das comunidades que habitavam as margens do corpo hídrico em tela, indicou que as unidades residenciais eram interligadas por pequenas pontes de madeira (Figura 8a), que cruzavam o igarapé. $\mathrm{O}$ deslocamento involuntário/compulsório deles era efetuado a pé, de bicicletas e até de motos. Esses fatores proporcionavam condições para que a degradação se acentuasse, além de ser foco de disseminação de muitas doenças (Ex.: dengue, malária, diarreia, micoses, etc.) veiculadas por insetos sinantrópicos (Ex.: Aedes aegipty), tudo isso somado ao risco periódico de enchentes no local que tornam o deslocamento da comunidade um fator de risco (Figura 8b). 
Figura 8. a) Via de mobilidade pública que permitia o trânsito dos residentes; b) as pontes e o estado de conservação insuficiente que durante as cheias, dificultam o trânsito dos moradores.

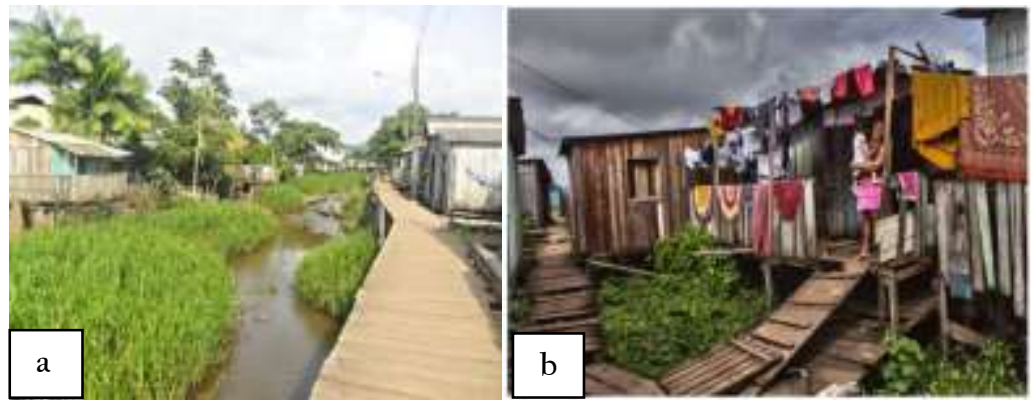

Fonte: Autores (2019).

Um fato ambiental não controlável: as cheias do Xingu que provocava mais ações negativas nessas áreas ambientalmente vulneráveis. Sobre essa vulnerabilidade Negrão et al. (2015), realizaram uma pesquisa sobre a origem da cidade objeto dessa pesquisa, e os dados que obtiveram os permitiu escrever que essa área é habitada por uma população com hipossuficiência econômica, e que estão sujeitas intempéries causadas pelas as cheias periódicas do Xingu (Ex.: dificuldades de trânsito no local), além dos danos econômicos aos 348 estabelecimentos comerciais instalados nessa área. Então, os impactos causados quando da ocupação dessa área foram identificados nos três meio diagnosticados e avaliados.

No contexto do impacto socioambiental, Silva e Lucas (2019), efetuaram estudos sobre os ribeiros e a hidrelétrica de Belo Monte, e concluiram que essa construção provoca deslocamento compulsório nessa comunidade, e uma das consequências disso é a perda do cultivo agrícola que ocorre nessa área, especialmente a de uso medicina, comercial e uso alimentar.

\subsection{Avaliação qualitativa e quantitativa da situação antes da recuperação do igarapé Altamira}

A análise dos dados obtidos indicou a ocorrência de vinte e dois impactos antes da recuperação ambiental em ambas as margens do Igarapé Altamira (Quadro 2). 
Quadro 2. Dados qualitativos e quantitativos dos impactos ambientais identificados no Igarapé Altamira - PA.

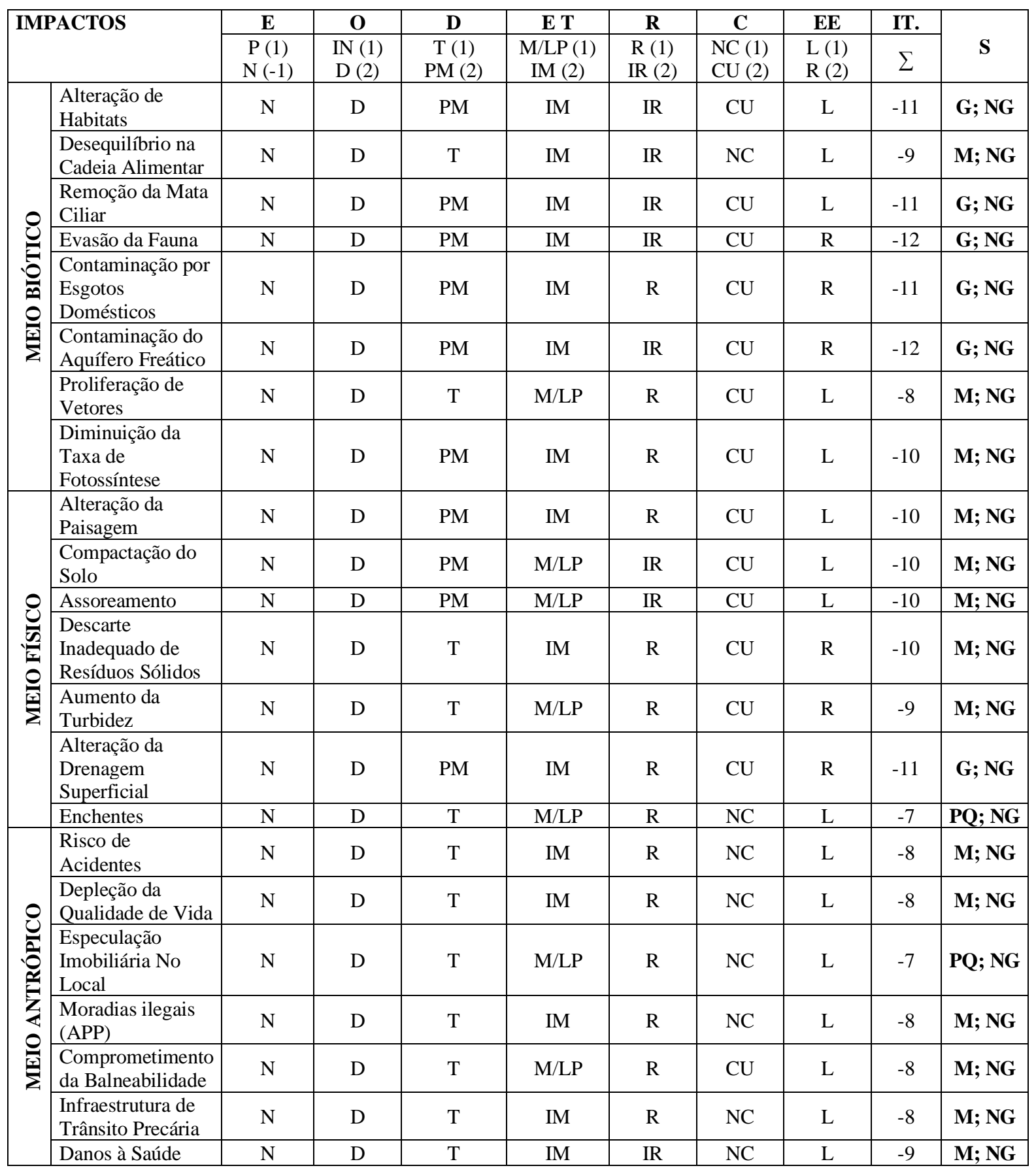

Legendas: $\mathbf{E}=$ Expressão $(\mathbf{P}=$ Positivo; $\mathbf{N}=$ Negativo $) ; \mathrm{O}=$ Origem $(\mathbf{D}=$ Direto; $\mathbf{I N}=$ Indireto $) ; \mathrm{D}=$ Duração $(\mathbf{T}=$ Temporário; $\mathbf{P M}=$ Permanente); ET = Escala Temporal $(\mathbf{I M}=$ Imediato; $\mathbf{M} / \mathbf{L P}=$ Médio ou Longo Prazo); $\mathbf{R}=$ Reversibilidade $(\mathbf{I R}=$ Irreversível; $\mathbf{R}=$ Reversível); $\mathbf{C}=$ Cumulatividade $(\mathbf{C U}=$ Cumulativo; $\mathbf{N C}=$ Não Cumulativo $) ; \mathbf{E E}=$ Escala Espacial $(\mathbf{L}=\mathrm{Local} ; \mathbf{R}=\mathrm{Regional}) ; \mathbf{I} . \mathbf{T}=$ Impacto Total; $\mathbf{S}=$ Significância (PQ = Pequena; $\mathbf{M}=$ Média; $\mathbf{G}=$ Grande; PS = Positiva; NG = Negativa). Fonte: Autores (2020).

A análise indicou que todos os impactos provenientes das ocupações de ambas as margens do Igarapé são de natureza negativa e direta. Pesquisa realizada em Roraima - RR, por Silva e Oliveira (2008), indicou que a legislação ambiental brasileira não é aplicada na íntegra, e isso gera agressões ambientais severas. Outro efeito atinge o meio socioambiental, e isso provoca ocupações marginais em APP's, onde as infraestruturas urbanas são ausentes (Ex.: transporte adequado, segurança, esgotamentos sanitários) o que determina uma diminuição da na qualidade de vida dessas populações. 
Para o MEIO BIÓTICO, a análise dos dados indicou um valor médio $(-10,5)$, significância "média" e de natureza negativa, logo, esse meio foi o que sofreu maior degradação ambiental, quando se fez a comparação com os valores obtidos para o Meio Físico $(-9,6)$ e o Meio Antrópico (-8).

A análise também indicou que duas variáveis (contaminação de aquífero freático e evasão de fauna) com valor igual a (-12), reafirmam a classificação da significância aplicada. Por isso, conclui-se que há uma relação de causa - efeito entre os impactos com grande significância como, por exemplo, a evasão da fauna $(\mathrm{V}=-12)$, que é ocasionado pela alteração de habitat (V = -11), e este, é consequência da perda da mata ciliar (-11), e consequentemente, no corpo hídrico, ocorreu aumento da turbidez (-9).

Pesquisa efetuada por Sànchez (2013), indicou que a maioria das formas de poluição reduz a complexidade do ecossistema, eliminando as espécies mais sensíveis. Isso corrobora com os resultados indicados para o Meio Biótico, pois, os valores obtidos e a natureza dos impactos conduzem a isso.

Em relação ao MEIO FÍSICO, a análise dos resultados indicou um valor médio igual a $(-9,6)$ logo, significância "média", porém, os valores numéricos obtidos $\left(\mathrm{V}_{\text {mín }}=-7\right.$, enchentes; $\mathrm{V}_{\text {máx }}=-11$, para alteração da drenagem superficial), demonstraram que também houve classificação da significância em "pequena" e "grande". Em face desses resultados, fica evidente a relação entre a alteração na drenagem superficial e as enchentes.

Os dados também indicaram que quatro componentes ambientais (alteração de paisagem, compactação do solo, assoreamento e descarte inadequado de resíduos sólidos) obtiveram valores semelhantes (-10), logo, significância de grau médio. Todavia, $44 \%$ dos indivíduos amostrados, relataram que o impacto mais significante, durante a ocupação da área, era a disposição inadequada de resíduos sólidos ao longo do corpo hídrico, que causava intensa poluição visual na área.

Estudo efetuado em Salvador - BA por Santos e Carvalho (2009), concluiu que a visão é o sentido de maior relevância para o homem, sendo capaz de captar um grande número de dados e de determinar reações, por isso, à poluição visual causada pelos resíduos sólidos, pode causar insegurança, assim como descaracterizar paisagens apreendidas no tempo pelo cidadão. Os dados obtidos na pesquisa realizada em Altamira, em relação aos indivíduos amostrados, são similares aos identificados em Salvador.

Quanto ao MEIO ANTRÓPICO, as análises dos dados obtidos indicaram que, este meio obteve a menor média (-8), significância como "média", embora a natureza dos impactos ainda seja negativa. Isso é explicado a partir da análise dos valores para outros componentes ambientais $\left(\mathrm{V}_{\text {mín }}=-7\right.$, especulação imobiliária no local; $\mathrm{V}_{\text {máx }}=-8$, risco de acidentes, depleção da qualidade de vida, comprometimento da balneabilidade, infraestrutura de trânsito precária).

Em relação aos danos à saúde, os dados indicaram um valor igual a -9 , significância média. Isso porque $54 \%$ (cinquenta e quatro por cento) dos indivíduos amostrados confirmaram que, pelo menos a um ano, houve ocorrência, na comunidade, de algum tipo de enfermidade (Ex.: dengue e diarreia), as quais podem estar relacionadas com esses fatores.

Pesquisa efetuada em Manaus - AM, por Giatti et al. (2010), indicou que, geralmente, a população não está devidamente informada sobre os riscos expostos quanto a contaminação do ambiente, do mesmo modo, não reconhece os malefícios à saúde, contribuindo para a permanência do próprio processo de exposição no local.

Os dados obtidos e analisados para a reversibilidade dos impactos indicaram que, dos vinte e dois identificados e classificados, $63 \%$ (sessenta e três por cento) são reversíveis, se empregadas ações corretivas, porém, dificilmente ocorreram ações desse tipo na área. No estudo efetuado no Rio Sanhauá - PB, por Barbosa e Furrier (2013), os autores concluíram que pouco se tem visto, a partir de ações mitigatórias, melhoria na qualidade de vida da população de baixa renda que ocupa irregularmente áreas de interesse ambiental, tão pouco, tem havido esforços para recuperar e preservar o ambiente ocupado por tais. 
Quanto à escala espacial, a análise dos dados indicou que 73\% (setenta e três por cento) dos impactos são de origem local, e que a maioria dos impactos regionais, estão ligados à qualidade do corpo hídrico, haja vista, que o Igarapé Altamira é um tributário do Rio Xingu, o qual banha outros munícipios do Pará, e poderá conduzir a poluição despejada nele para outras localidades. Pesquisa efetuada no Rio Negro - AM, por Pinto et al. (2009), indicou que os efeitos das atividades antrópicas nos igarapés tributários refletem na qualidade do Rio Negro. Isso estava ocorrendo no Rio Xingu devido a ocupação indevida das margens do Igarapé Altamira.

Em relação a classificação dos impactos em função da natureza, os dados indicaram situações diferentes para o Igarapé Altamira (Tabela 1).

Tabela 1. Percentual da classificação da Natureza dos impactos e a classificação da significância.

\begin{tabular}{c|c|c}
\hline Quantidade de Impactos & Significância e Natureza. & Porcentagem (\%) \\
\hline 02 & Pequena (-6 $\geq-7)$ & $9 \%$ \\
15 & Média $(-8 \geq-10)$ & $68 \%$ \\
05 & Grande $(-11 \geq-12)$ & $23 \%$ \\
\hline 22 & TOTAL & $100 \%$ \\
\hline
\end{tabular}

Fonte: Autores (2019).

Tal analise indicou uma significância média em face do valor obtido (68\%). Todavia, a gravidade da agressão sofrida pelo igarapé Altamira é crescente, pois o valor obtido (23\%) pertence a um grau de significância "grande". Isso pode indicar uma evolução do estágio de significância média para grande, devido as agressões ambientais ulteriores e ainda não mitigadas, e o desequilíbrio na sustentabilidade desejada para Áreas de Preservação Permanente (APP).

Pesquisa efetuada em no Igarapé do Gigante, em Manaus - AM, por Braga et al. (2012), indicou que a ocupação do solo urbano às margens dos igarapés tem acarretado uma série de consequências ao meio natural, como a supressão e degradação das áreas verdes e de preservação permanente, a falta de saneamento básico e a destinação final dos resíduos, gera ambientes insalubres e com baixa qualidade de vida. Esses dados são consonantes aos encontrados na análise efetuada às margens do Igarapé Altamira, na situação que antecederam as ações da Norte Energia nesse local.

\subsection{A situação da área após a recuperação das margens do igarapé Altamira}

Os dados obtidos e analisados indicaram que deslocamento involuntário/compulsório das famílias residentes nas imediações do Igarapé Altamira, iniciou em 2014, para novas áreas da cidade, à medida que as pessoas eram retiradas, as palafitas onde residiam foram demolidas (Figura 9a) e isso gerou um novo território urbano (Figura 9b).

Figura 9. Vista aérea das margens do Igarapé Altamira a) antes da ação restauradora e b) depois dessa ação. Altamira, Pará.

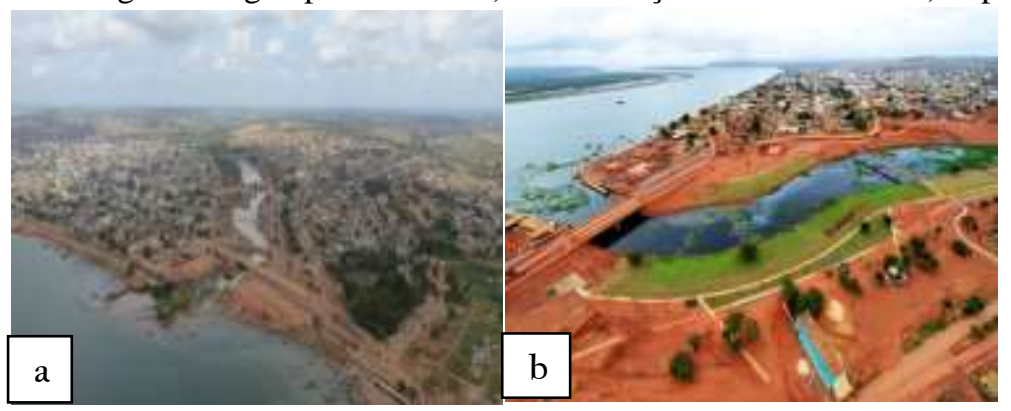

Fonte: Norte Energia (2015; 2016a). 
Quanto ao crescimento da malha urbana em várias direções em Altamira, Miranda Neto e Herrera (2017), analisaram esse fato nesse município e argumentaram que tal crescimento está atrelado a instalação da Usina Hidrelétrica de Belo Monte (UHBM), e destacam que a tríade responsável por tudo isso é composta pelo Poder Público, agentes imobiliários e a Norte Energia S/A, especialmente como ordenadores desse território. Nessa pesquisa, foi evidenciado que esses ordenadores náo conseguiram, de forma efetiva, dinamizar à comunidade que residia às margens do Igarapé Altamira, já que nem todas as famílias foram contempladas com tais melhorias.

Em relação a não contemplação do total de famílias que ali habitavam, a análise dos dados indicou também que duzentas e quarenta e quatro residências permanecem às imediações do Igarapé em condições similares a situação-base (Figura 10a). A urbanização parcial (Figura 10b) modificou a paisagem cênica, todavia, o cuidado ambiental não foi evidenciado no local já que havia deposição de resíduos sólidos em áreas pós urbanizadas (Figura 10c).

Figura 10. a) estado das palafitas que ainda permanecem às margens do Igarapé Altamira; b) passarelas e ciclovias após a intervenção da Norte Energia; c) Deposição de resíduos sólidos na área pós urbanizada. Altamira - Pará.

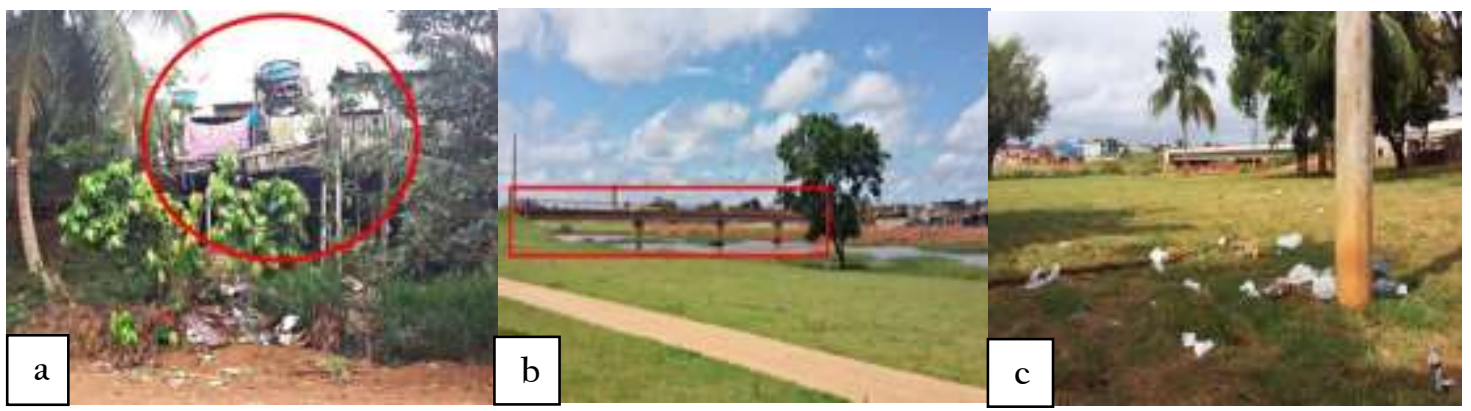

Fonte: Autores (2020).

Acerca da existência de comunidades ainda não contempladas pela urbanização, Borges et al. (2020), efetuaram estudo sobre o processo de urbanização no município de Fagundes - PB, e concluiram que há problemas ambientais oriundos do crescimento populacional e que afetam o meio socioambiental como, por exemplo, povoamento irregular, pois, para eles, as duas expansões (da população e a urbana), não podem sofrer solução de continuidade. Na pesquisa realizada em Altamira, esses aspectos foram identificados, qualificados e quantificados, já que população de Altamira, em área urbana, cresceu: 1950 = 1.809 habitante; 2010 = 84.092 habitantes. Então, a urbanização onde quer que ela ocorra, é necessário um planejamento eficaz para evitar danos dessas naturezas.

Os dados analisados após a recuperação das margens do Igarapé Altamira, indicaram que: (1) ainda está ocorrendo a recepção de efluentes domésticos in natura no corpo hídrico pesquisado (Figura 11a), em consequência disso, houve intensa proliferação de macrófitas no Igarapé Altamira (Figura 11b). (2) a ocorrência de outro impacto ambiental: o alargamento do canal do Igarapé Altamira (11c) e o assoreamento de áreas ao longo do corpo hídrico (Figura 11d). 
Figura 11. a) Recepção de esgoto doméstico no corpo hídrico analisado; b) crescimento de macrófitas em função da recepção do esgoto; c) Alargamento do Igarapé Altamira; d) assoreamento ao longo desse corpo hídrico. Altamira, Pará.

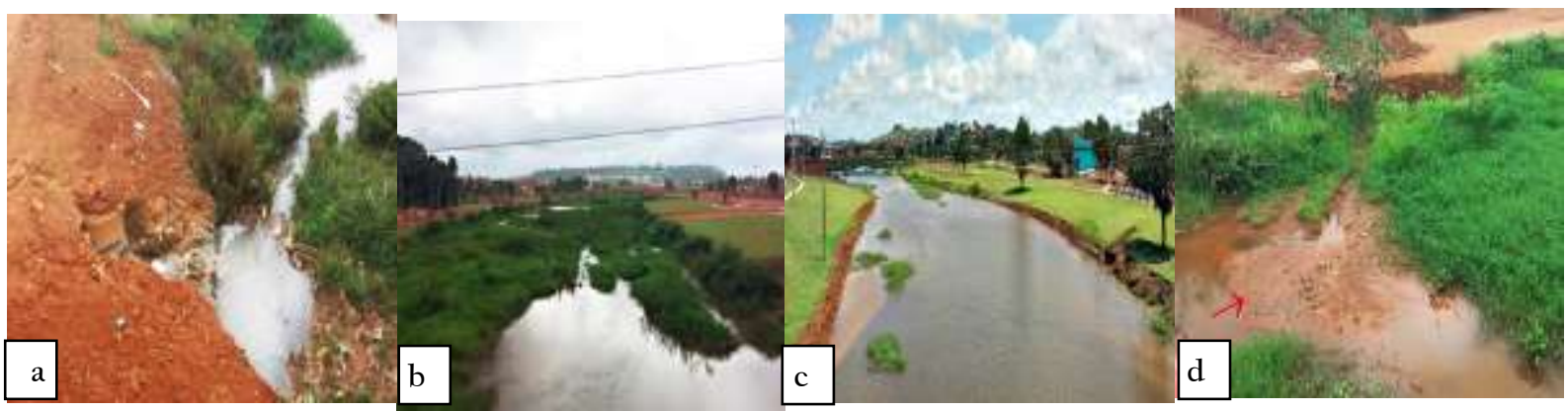

Fonte: Autores (2020).

Todavia, o processo de urbanização e modificação da paisagem cênica apresenta deficiência quanto aos efluentes domésticos, pois há presença de anilhas de concreto que desaguam no igarapé Altamira. Todavia, no Projeto Básico Ambiental, versão final (2011, p.12), item2, que haveria "uma adequação ao sistema de esgotamento sanitários nas áreas marginais dos igarapés, de forma a restringir o aporte de nutrientes aos mesmos". Todavia, comprovou-se que isso ainda não ocorreu, pois há desague de efluente direto no Igarapé Altamira.

Um complexo de lazer a disposição da comunidade (pista para caminhada, quadras de areia poliesportiva, mesas de xadrez, pista de skate e playground infantil (Figura 12a). (4) implantação de cobertura vegetal (Figura 12b), arborização e paisagismo e calçamentos (Figura 12c). Todavia, ainda não alcançaram toda a área prevista, já que existem áreas que ainda não foram contempladas com a cobertura vegetal e novo paisagismo (Figura 12d).

Figura 12 - a) Quadra de areia; b) cobertura vegetal já implantada; c) área sem a cobertura vegetal; d) novo paisagismo incompleto. Altamira, Pará.

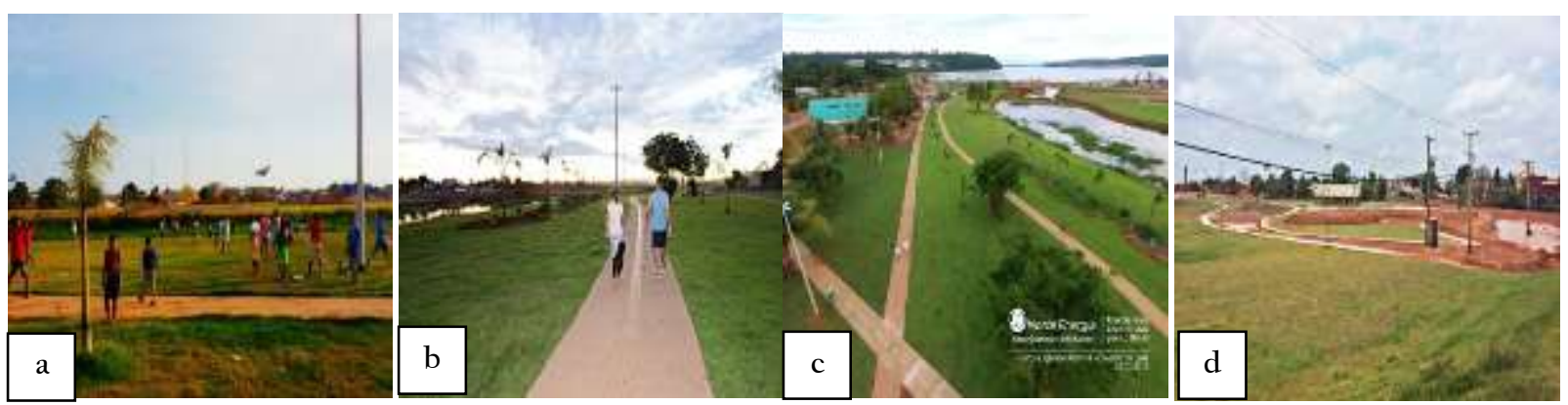

Fontes: autores (2020); Norte Energia (2015; 2016 b, d) e Mendes et al. (2020).

Todo processo de urbanização em áreas críticas, como o igarapé Altamira, deve proporcionar à comunidade uma nova relação com o meio em que vivem. Sobre essa relação, Mendes et al. (2018), efetuara estuo em dois bairros da cidade de Altamira - PA. Eles concluiram que houve significativas mudanças na relação entre homem-meio ambiente em face dos novos espaços de lazer e sociabilidade, o que elevou a capacidade proativa para usufruir dele. Nessa pesquisa, isso foi comprovado nas áreas onde a urbanização marginal do igarapé, já se concretizou e foram inseridos como impactos positivos.

\subsection{Avaliação qualitativa e quantitativa após a recuperação das margens do igarapé Altamira}

$\mathrm{Na}$ avaliação após a recuperação das margens do Igarapé Altamira, verificou-se 23 impactos, os quais ocorreram nos três meios componentes do ambiente, sendo que $48 \%$ dos impactos estão alocados no meio físico, e $26 \%$ dos impactos estão no 
meio biótico e antrópico, respectivamente. Esses impactos são provenientes da interferência para realização das obras necessárias para recuperar a área e da população circunvizinha do Igarapé Altamira (Quadro 3).

Quadro 3. Impacto ambientais identificados, qualificados e quantificados após recuperação marginal do Igarapé Altamira PA.

\begin{tabular}{|c|c|c|c|c|c|c|c|c|c|c|}
\hline & $\mathbf{E}$ & O & D & $\mathbf{E} \mathbf{T}$ & $\mathbf{R}$ & $\mathrm{C}$ & $\mathbf{E E}$ & I. T. & \multirow[b]{2}{*}{$\mathbf{S}$} \\
\hline & & $\begin{array}{l}\mathrm{P}(1) \\
\mathrm{N}(- \\
1) \\
\end{array}$ & $\begin{array}{l}\mathrm{IN}(1) \\
\mathrm{D}(2)\end{array}$ & $\begin{array}{l}\text { T (1) } \\
\operatorname{PM}(2)\end{array}$ & $\begin{array}{l}\text { M/LP (1) } \\
\text { IM (2) }\end{array}$ & $\begin{array}{l}\mathrm{R}(1) \\
\mathrm{IR} \\
(2) \\
\end{array}$ & $\begin{array}{l}\mathrm{NC}(1) \\
\mathrm{CU}(2)\end{array}$ & $\begin{array}{l}\mathrm{L}(1) \\
\mathrm{R}(2)\end{array}$ & $\Sigma$ & \\
\hline \multirow{6}{*}{ 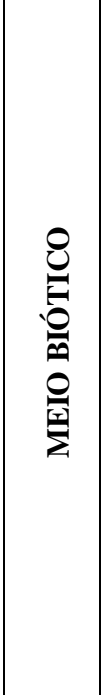 } & $\begin{array}{l}\text { Contaminação por } \\
\text { Esgoto Doméstico }\end{array}$ & $\mathrm{N}$ & $\mathrm{D}$ & $\mathrm{T}$ & IM & $\mathrm{R}$ & $\mathrm{NC}$ & $\mathrm{L}$ & -8 & M; NG \\
\hline & $\begin{array}{l}\text { Contaminação do } \\
\text { Aquífero Freático }\end{array}$ & $\mathrm{N}$ & $\mathrm{D}$ & PM & IM & IR & $\mathrm{CU}$ & $\mathrm{L}$ & -11 & G; NG \\
\hline & $\begin{array}{l}\text { Cobertura Vegetal e } \\
\text { Arborização do Local }\end{array}$ & $\mathrm{P}$ & $\mathrm{D}$ & PM & M/LP & IR & $\mathrm{CU}$ & $\mathrm{L}$ & 10 & M; PS \\
\hline & $\begin{array}{l}\text { Incremento da } \\
\text { Microflora e } \\
\text { Microfauna }\end{array}$ & $\mathrm{P}$ & IN & PM & M/LP & IR & $\mathrm{CU}$ & $\mathrm{L}$ & 9 & M; PS \\
\hline & $\begin{array}{l}\text { Proliferação de } \\
\text { Macrófitas }\end{array}$ & $\mathrm{N}$ & IN & $\mathrm{T}$ & IM & $\mathrm{R}$ & $\mathrm{CU}$ & $\mathrm{L}$ & -8 & M; NG \\
\hline & $\begin{array}{l}\text { Aumento da Taxa de } \\
\text { Fotossíntese }\end{array}$ & $\mathrm{P}$ & IN & PM & M/LP & IR & $\mathrm{NC}$ & $\mathrm{L}$ & 8 & M; PS \\
\hline \multirow{11}{*}{ 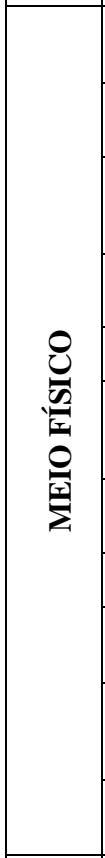 } & $\begin{array}{l}\text { Alteração da } \\
\text { Paisagem }\end{array}$ & $\mathrm{P}$ & $\mathrm{D}$ & $\mathrm{PM}$ & IM & IR & $\mathrm{CU}$ & $\mathrm{R}$ & 12 & G; PS \\
\hline & $\begin{array}{c}\text { Alteração } \\
\text { Microclimática }\end{array}$ & $\mathrm{P}$ & IN & PM & IM & IR & $\mathrm{NC}$ & $\mathrm{L}$ & 9 & M; PS \\
\hline & $\begin{array}{c}\text { Melhoria na } \\
\text { Qualidade da Água }\end{array}$ & $\mathrm{P}$ & $\mathrm{D}$ & PM & $\mathrm{IM}$ & IR & $\mathrm{CU}$ & $\mathrm{R}$ & 12 & G; PS \\
\hline & $\begin{array}{c}\text { Melhoria na } \\
\text { Qualidade do Ar }\end{array}$ & $\mathrm{P}$ & $\mathrm{D}$ & PM & IM & IR & $\mathrm{NC}$ & $\mathrm{L}$ & 10 & M; PS \\
\hline & Assoreamento & $\mathrm{N}$ & $\mathrm{D}$ & $\mathrm{PM}$ & $\mathrm{M} / \mathrm{LP}$ & IR & $\mathrm{CU}$ & $\mathrm{L}$ & -10 & M; NG \\
\hline & $\begin{array}{c}\text { Alteração da } \\
\text { Drenagem Superficial }\end{array}$ & $\mathrm{P}$ & $\mathrm{D}$ & PM & M/LP & IR & $\mathrm{CU}$ & $\mathrm{R}$ & 11 & G; PS \\
\hline & $\begin{array}{l}\text { Dispersão de gases e } \\
\text { poeiras }\end{array}$ & $\mathrm{N}$ & $\mathrm{D}$ & $\mathrm{T}$ & IM & $\mathrm{R}$ & $\mathrm{NC}$ & $\mathrm{L}$ & -8 & M; NG \\
\hline & Poluição Sonora & $\mathrm{N}$ & $\mathrm{D}$ & $\mathrm{T}$ & $\mathrm{IM}$ & $\mathrm{R}$ & $\mathrm{NC}$ & $\mathrm{L}$ & -8 & M; NG \\
\hline & $\begin{array}{l}\text { Descarte Inadequado } \\
\text { de Resíduos Sólidos }\end{array}$ & $\mathrm{N}$ & $\mathrm{D}$ & $\mathrm{PM}$ & $\mathrm{IM}$ & $\mathrm{R}$ & $\mathrm{CU}$ & $\mathrm{L}$ & -10 & M; NG \\
\hline & $\begin{array}{l}\text { Aumento do Canal do } \\
\text { Igarapé Altamira }\end{array}$ & $\mathrm{N}$ & $\mathrm{D}$ & PM & IM & IR & $\mathrm{NC}$ & $\mathrm{L}$ & -10 & M; NG \\
\hline & $\begin{array}{c}\text { Diminuição da } \\
\text { Turbidez }\end{array}$ & $\mathrm{P}$ & IN & PM & M/LP & IR & $\mathrm{CU}$ & $\mathrm{R}$ & 10 & M; PS \\
\hline \multirow{4}{*}{ 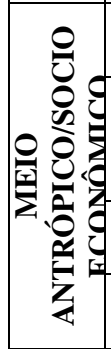 } & $\begin{array}{c}\text { Geração de Emprego } \\
\text { e Renda }\end{array}$ & $\mathrm{P}$ & $\mathrm{D}$ & $\mathrm{T}$ & M/LP & $\mathrm{R}$ & $\mathrm{NC}$ & $\mathrm{L}$ & 7 & PQ; PS \\
\hline & $\begin{array}{l}\text { Alteração das } \\
\text { Relações } \\
\text { Socioculturais }\end{array}$ & $\mathrm{N}$ & $\mathrm{D}$ & PM & IM & IR & $\mathrm{NC}$ & $\mathrm{L}$ & -10 & M; NG \\
\hline & $\begin{array}{c}\text { Aumento da } \\
\text { Qualidade de Vida } \\
\end{array}$ & $\mathrm{P}$ & $\mathrm{D}$ & PM & $\mathrm{IM}$ & IR & $\mathrm{NC}$ & $\mathrm{L}$ & 10 & M; PS \\
\hline & $\begin{array}{l}\text { Aumento da } \\
\text { Violência }\end{array}$ & $\mathrm{N}$ & IN & $\mathrm{T}$ & M/LP & $\mathrm{R}$ & $\mathrm{NC}$ & $\mathrm{L}$ & -6 & PQ; NG \\
\hline
\end{tabular}




\begin{tabular}{|c|c|c|c|c|c|c|c|c|c|}
\hline $\begin{array}{c}\text { Melhoria na } \\
\text { Infraestrutura do } \\
\text { Trânsito } \\
\end{array}$ & $\mathrm{P}$ & D & PM & IM & IR & $\mathrm{CU}$ & $\mathrm{R}$ & 12 & G; PS \\
\hline $\begin{array}{c}\text { Criação de Áreas de } \\
\text { Lazer }\end{array}$ & $P$ & $\mathrm{D}$ & $\mathrm{PM}$ & $\mathrm{IM}$ & IR & $\mathrm{CU}$ & $\mathrm{R}$ & 12 & G; PS \\
\hline
\end{tabular}

Legendas: $\mathbf{E}=$ Expressão $(\mathbf{P}=$ Positivo; $\mathbf{N}=$ Negativo $) ; \mathrm{O}=$ Origem $(\mathbf{D}=$ Direto; $\mathbf{I N}=$ Indireto $) \mathrm{D}=$ Duração $(\mathbf{T}=$ Temporário; $\mathbf{P M}=$ Permanente); ET = Escala Temporal $(\mathbf{I M}=$ Imediato; $\mathbf{M} / \mathbf{L P}=$ Médio ou Longo Prazo); $\mathbf{R}=$ Reversibilidade $(\mathbf{I R}=$ Irreversível; $\mathbf{R}=$ Reversível); $\quad \mathbf{C}=$ Cumulatividade $(\mathbf{C U}=$ Cumulativo; $\mathbf{N C}=$ Não Cumulativo $) ; \mathbf{E E}=$ Escala Espacial $(\mathbf{L}=$ Local; $\mathbf{R}=$ Regional $) ; \mathbf{I} . \mathbf{T} .=$ Impacto Total; $\mathbf{S}=$ Significância $(\mathbf{P Q}=$ Pequena; $\mathbf{M}=$ Média; $\mathbf{G}=$ Grande; $\mathbf{P S}=$ Positiva; NG = Negativa). Fonte: Autores (2020).

Os dados obtidos e analisados indicaram que, dos vinte e três impactos ambientais identificados, $57 \%$ foram avaliados como positivos, os mesmos, também foram classificados, maioritariamente, como permanentes, e isso indicou uma recuperação da área em análise e melhorias no meio ambiente. Pesquisa efetuada no Rio Dona Eugênia - RJ, por Costa et al. (2013), indicou que é possível reverter um cenário de gradual degradação ambiental e transformá-lo em um novo cenário de requalificação urbana, recuperando o ecossistema contaminado.

A análise dos dados para o MEIO BIÓTICO, indicaram um valor para a média da significância entre: $\mathrm{V}_{\text {mín }}=8$; $\mathrm{V}_{\text {máx }}$. $=10$, positivo, e $\left(\mathrm{V}_{\text {mín }=-8 ;} \mathrm{V}_{\text {máx }}=-11\right)$ negativa. A quantidade de impactos foi equivalente para cada expressão. A média da significância para expressão positiva e negativa foi similar (+9 e -9), o que determina a significância como "média". Houve também indicação de que, no meio biótico, os impactos positivos foram: cobertura vegetal e arborização do local (V = 10), que como consequência aumenta a taxa de fotossíntese $(\mathrm{V}=8)$ que viabiliza o aumento da microflora e microfauna (V=9) no ambiente.

Quanto ao MEIO FÍSICO, a análise dos dados obtidos indicou a ocorrência de impactos positivos e negativos. Os impactos negativos obtiveram valores de média: $V_{\text {mín }}-8 ; V_{\text {máx }}=-10$. $O$ valor médio para a significância foi igual a $-9,2$, logo, média. Os impactos positivos obtiveram valores $\mathrm{V}_{\text {mín }}=9$ e $\mathrm{V}_{\text {máx }}=12$. Isso indicou um grau de significância “grande".

Os dados também indicaram que houve modificação quando a natureza do impacto ambiental ocorrido na paisagem cênica, pois, antes das ações interventoras, era classificada como de natureza negativa $(\mathrm{V}=-10)$, atualmente, encontra-se como natureza positiva $(\mathrm{V}=12)$, pois, ambiente com paisagens agradáveis além de indicarem equilíbrio ambiental também proporcionam a comunidade diversos benefícios e melhoram a percepção ambiental da comunidade.

Na pesquisa realizada em Teresina - PI, por Vieira et al. (2020), sobre arborização urbana e a evolução temporal da paisagem, os autores obtiveram dados que os permitiram escrever: os locais outrora abandonados devido a fatores múltiplos, permitem a criação de áreas verdes e gerar lazer pra a zona urbana. A análise dos dados obtidos em Altamira indicou tais contribuições.

No MEIO ANTRÓPICO, os dados obtidos indicaram a ocorrência de impactos positivos (67\%, onde foram incluídos: criação do complexo de lazer, melhoria na infraestrutura de trânsito e a geração de emprego e renda) e negativos (33\%, onde se inclui a alteração das relações socioculturais), logo, grau médio. É importante ressaltar que, dos três meios analisados, o antrópico, alcançou o menor valor (-8) para significância de natureza negativa, houve indicação também de este foi o único meio que apresentou significância classificada como "pequena".

Estudo realizado em Ananindeua - PA, por Costa et al. (2016), concluiu que as ações de intervenção em áreas de assentamentos informais que implicam em remanejamento e reassentamento de pessoas, têm gerado a demanda pela adaptação dos moradores a esses novos ambientes de moradia e exigido deles um esforço em superar as dificuldades geradas pela perda de laços estabelecidos com o antigo contexto.

Após a urbanização da área em estudo, foram identificados 10 impactos de natureza negativa e significância classificada entre pequena a grande (Tabela 2). 
Tabela 2. Impactos ambientais negativos e positivos e a significância identificados após a urbanização no Igarapé Altamira PA.

IMPACTOS AMBIENTAIS NEGATIVOS

\begin{tabular}{ccc}
\hline Quantidade de Impactos & Significância e Natureza & Porcentagem (\%) \\
\hline 01 & Pequena $(-6 \geq-7)$ & $4 \%$ \\
08 & Média $(-8 \geq-10)$ & $35 \%$ \\
01 & Grande $(-11 \geq-12)$ & $4 \%$ \\
10 & TOTAL & $100 \%$ \\
\hline 01 & Pequena $(6 \geq 7)$ & $4 \%$ \\
07 & Média $(8 \geq 10)$ & $31 \%$ \\
05 & Grande $(11 \geq 12)$ & $22 \%$ \\
\hline
\end{tabular}

Fonte: Autores (2020).

Pesquisa efetuada na Lagoa Pirapitinga - MG, por Teixeira (2016) indicou que a revitalização do corpo aquático transforma um ambiente degradado em um local destinado a lazer, estudos e recreação, aliado a criação de um parque ecológico, com ações destinadas à proteção e preservação do meio ambiente. Esse resultado é consonante ao obtido nessa pesquisa.

\section{Conclusão}

Os impactos ambientais ocorridos no Igarapé Altamira, a partir da ocupação das margens, persistiram até o início das ações intervencionistas da Norte Energia. Após a intervenção, a maioria desses impactos foram mitigados e atenuados, mas ainda há ocorrência de impactos que atuam sobre a qualidade de vida da comunidade que ora habita o entorno desse corpo hídrico devido a criação de uma Unidade de Conservação (UC).

Verificou-se que, a situação inicial foi mitigada, e os impactos negativos ainda ocorrentes devem ser sanados com o término da obra para que o objetivo da empresa, quanto a criação da Unidade de Conservação, seja alcançado. Portanto, a atual situação a margem do Igarapé Altamira apresenta-se em franca recuperação, mas, vale ressaltar que a comunidade local usuária dessa área já pratica ações negativas que ameaçam a manutenção da qualidade ambiental dessas margens.

Sugere-se que os órgãos ambientais municipais e as instituições de ensino superior, monitorem com frequência semestral, a qualidade de vida da comunidade que sofreu deslocamento involuntário ou compulsório, e elaborar um banco de dados para analisar a evolução dos impactos ambientais e o equilíbrio da qualidade de vida, bem como agir de forma direta e eficaz para mitigar e/ou incrementar ações que promovam a conservação ambiental, sem frenar ou retardar o desenvolvimento econômico e social.

\section{Referências}

Alves, B. R., \& Coelho, M. T. (2020) Usina hidrelétrica de Belo Monte: a desterritorialização dos ribeiros do Rio Xingu. https://www.archdaily.com.br/br/941563/usina-hidreletrica-de-belo-monte-a-desterritorializacao-dos-ribeirinhos-do-rio-xingu

Amorim, E. L. C. (2011). Avaliação de Impactos Ambientais. Universidade Federal de Alagoas. http://www.ctec.ufal.br/professor/elca/AIA12011_2.htm>.

Barbosa. T. S. \& Furrier. M. (2013) Ocupações Irregulares e Impactos Socioambientais Às Margens Do Rio Sanhauá, Paraíba/Brasil. Revista Percurso. NEMO. 5(2),91- 107.

Borges, I. M. S., Lima, C. A. O., Fernandes, A. C. G., Nunes, E. A. C., Alves, A. E. F., Nunes, E. A. C., Nunes, F. J. B., Rocha, A. L. S. Santos Júnior, C. N., \& S., Batista, A. C. (2020) O processo de urbanização e seus imapctos ambientais na cidade de Fagundes, Paraíba, recortes históricos. Research, Society and Development, 9(8), E345985196. 
Braga, K. A. A. F., Silva, F. F., \& Schaffrath, V. R. (2012). Microbacia do Igarapé do Gigante: Unidade de Planejamento para A Gestão da Bacia do Tarumã. Revista em Agronegócios e Meio Ambiente, 5(1), 103-129.

Brasil. Decreto $\mathrm{n}^{\circ}$ 4.297, de 10 de julho de 2002. Regulamenta o art. 9, inciso II, da Lei n. 6.938, de 31 de agosto de 1981, estabelece critérios para o Zoneamento Ecológico-Econômico do Brasil - ZEE, e dá outras providências. Diário Oficial [da] República Federativa do Brasil, Poder Executivo, Brasília, DF, 10 jul. 2002. Seção 1, p. 1.

Brito, F. A., \& Pinho, B. A. T. D. (2012). A dinâmica do processo de urbanização no Brasil, 1940-2010. UFMG/CEDELAR.

Costa, C. L., Lima, R. F., Paixão, G. C., \& Pantoja, D. M. (2012). Avaliação da qualidade das águas subterrâneas em poços do estado do Ceará, Brasil. Semina: Ciências Biológicas e da Saúde, 33(2),171-180.

Costa, D. R., Cavalcante, L. I. C., \& Afonso, T. (2016). Remanejamento, Reassentamento e Adaptação dos Moradores Ao Conjunto Habitacional Jader Barbalho-Ananindeua (PA), 1(1). In: Encontro Internacional de Política Social e Encontro Nacional de Política Social, 4. 11.Espírito Santos. Anais eletrônicos [...]. https://periodicos.ufes.br/einps/article/view/12995

Costa, I. A. A., Parent-Pothier, S., Nascimento, M. B., \& Britto, A. L. (0213). Revitalização Urbana e Ambiental de Rios Urbanos na Região Metropolitana do Rio de Janeiro: O caso do Rio Dona Eugênia em Mesquita. Semantic Scholar. https://www.semanticscholar.org/paper/Revitaliza\%C3\%A7\%C3\%A3o-urbanae-ambiental-de-rios-urbanos-na-Costa-Parent-Pothier/8f93490f3db301269983652cdfee42003c9d3dc4.

Dagnino, R. S. (2014). Mapa de localização dos municípios de Altamira e São Félix do Xingu. https://www.researchgate.net/project/URBISAmazonia.

Duarte, L. H. S. M., Basso, P. O., Albano, M. P., \& Maria, Y. R. (2013). A crise urbana ambiental e a carência do planejamento ambiental para o saneamento básico. Colloquium Humanarun, 10 (especial), 196-204.

Eletrobrás (2009). Estudo de Impacto Ambiental e Relatório de Impacto Ambiental - Aproveitamento Hidrelétrico Belo Monte. <www.internationalrivers.org/files/attached-files/rima.pdf>.

Farinaccio, A., \& Tessler, M. G. (2010). Avaliação de Impactos Ambientais no Meio Físico decorrentes de Obras de Engenharia Costeira - Uma Proposta Metodológica. Revista da Gestão Costeira Integrada, 10(4),419-434.

Freitas, A. L. A., Herrera, R. C., \& Herrera, J, A. (2016). Ocupação humana no igarapé do Gelo, Vitória do Xingu - PA. Revista do Instituto Histórico e Geográfico do Pará, 3(2), 01-12.

Gil, A. C. (2008). Como elaborar projetos de pesquisa. (4a ed.), Atlas.

Girelli, C. C. (2009) Ocupações irregulares em áreas úmidas: Análise da ocupação na ressaca Chico Dias e as consequências para o ambiente urbano. [Dissertação]. Macapá: Universidade Federal do Amapá.

Giatti, L. L., Neves, N. L. S., Saraiva, G. N., \& Toledo, R. F. (2010). Exposição à água contaminada: percepções e práticas em um bairro de Manaus, Brasil. Revista Panam Salud Publica, 28(5), 1-7.

Google Earth (2016). Localização do Igarapé Altamira. Altamira - PA, 2016. Escala 1:10.000

IBGE (2008). Mapas Temáticos. <www.mapas.ibge.gov.br/tematicos>.

IBGE (2015). Estimativas da população residente no Brasil e unidades da federação com data de referência em $1^{\circ}$ de julho de 2015 . ftp://ftp.ibge.gov.br/Estimativas_de_Populacao/Estimativas_2015/estimativa_dou_2015_20150915.pdf.

IBGE (2017) Cidades. Altamira. História. https://cidades.ibge.gov.br/brasil/pa/altamira/histórico

Lobato, A. A. C., Gouveia, P. M. S., Santos, T. S. S. \& Alvarez, W. P. A influência da bacia hidrográfica no clima urbano da Amazônia: análise do clima na bacia do igarapé Ambé no perímetro urbano de Altamira - PA, no período de implantação da UHE Belo monte, 2011 a 2015. In: Simpósio Brasileiro de Geografia Física e Aplicada, Congresso Nacional de Geografia Física. 17.1, 2017. São Paulo. Anais eletrônicos [...]. file:///C:/Users/Bio/Downloads/2449Texto\%20do\%20artigo-11262-1-10-20171003\%20(1).pdf

Luz, A. C. S., Freitas, J, S., \& Oliveira, R. D. (2012). Descarte de resíduos sólidos das construções civis na cidade de Altamira Pará. Revista Geonorte, 3(4), $84-93$

Mendes, F. J. C., Souza, C. M., \& Melo, G. E. L. (2018). Usina Hidrelétrica "Belo Monte": reflexos nas práticas de lazer em Altamira. Revista Brasileira de Ciência e Movimento, 26(4), 144-156.

Mendes, F. J. C., Sousa, C. A. M., Miranda Neto, \& J. Q. M. (2020) Lazer em Altamira - PA, e as transformações após a construção da Usina Hidrelétrica de Belo Monte. Ateliê Geográfico 14(2), 224-243.

MICROSOLFT CORPORATION. (2019). Funções do Excel (ordem alfabética). https://support.microsoft.com/pt-br/office/fun\%C3\%A7\%C3\%B5es-doexcel-ordem-alfab\%C3\%A9tica-b3944572-255d-4efb-bb96-c6d90033e188

Miranda Neto, J. Q., \& Herrera, J. A. Expansão urbana recente em Altamira (PA). Novas tendências de crescimento a partir da instalação de Belo Monte. Ateliê geográfico, 11(3), 34-52.

Neves, I. C., Carvalho G. B., Cornélio, G. S. (2016). Expansão urbana e segregação socioespacial: uma análise da cidade de Altamira -Pará face ao empreendimento hidrelétrico de Belo Monte. Revista do Instituto e Geográfico do Pará, 3(2), 99-116.

Norte Energia (2015). Vista aérea do Igarapé Altamira após retirada das palafitas. PA, 2015. <http://norteenergiasa.com.br/site/2016/02/22/parque-altamiramuda-paisagem-da-cidade/igarape-altamira-betto-silva-norte-energia-39-2/. 
Norte Energia (2016a). Vista superior da Zona Urbana do Igarapé Altamira. www2.mppa.mp.br/sistemas/gcsubsites/upload/41/M inistErio\%20PUblico\%20do\%20Estado\%20do\%20ParA-ApresentaCAo\%20dia\%2014Agosto2015-Final.pdf>.

Norte Energia (2016b). Vista aérea do início da cobertura vegetal no local. PA, 2016. <http://norteenergiasa.com.br/site/2016/02/22/parque-altamira-mudapaisagem-da-cidade/igarape-altamira-betto-silva-norte-energia-39-2/.

Norte Energia (2016c). Vista aérea da cobertura vegetal e arborização as margens do Igarapé Altamira. PA, 2016. http://norteenergiasa.com.br/site/2016/03/07/informe-norte-energia-31/.

Norte Energia. (2016d) Vista frontal da pista de caminhada. http://norteenergiasa.com.br/site/2016/03/07/informe-norte-energia-31/parque-igarape-altamirabetto-silva-norte-energia-8/.

PMA. (2010). Relatório do Plano Diretor (v. II). Prefeitura Municipal de Altamira. http://altamira.pa.gov.br/site/wp-content/uploads/2017/04/Vol-2Relat\%C3\%B3rio-do-Plano-Diretor-PDU.pdf

Pinto, A. G. N., Horbe, A. M. C., Silva, M. S. R., Miranda, S. A. F., Pascoa loto, D. \& Santos, H. M. C. (2009). Efeitos da ação antrópica sobre a hidrogeoquimicas do Rio Negro na orla de Manaus/AM. Acta Amazônica, 39(3), 623-630.et a

Pinto, J. G. (2008). Análise introdutória do processo de ocupação urbana em Manaus e suas consequências socioambientais: o estudo de caso das comunidades São Pedro, Arthur Reis e Bariri. [Dissertação]. Manaus. Universidade Federal do Amazonas.

Ramos, S. M., Giusti, D., A., Nadal, C. A., \& Ratton, E. (2017). Diagnostico da comunidade bentônica do licenciamento ambiental da ponte sobre o rio Corrente, Correntina - BA. Revista Brasileira de Gestão Ambiental, 11(1), 200-208.

Rush, E., \& Krull, A. (2015). Guia de orientação para Licenciamento Ambiental. https://cbic.org.br/wpcontent/uploads/2017/11/Guia_de_Orientacao_para_Licenciamento_Ambiental_2015-1.pdf

Sanchez, L. E (2013). Avaliação de Impacto Ambiental: conceitos e métodos. (2a ed.), Oficina de Textos.

Santana, M. N. R. (2011). Identificação Dos Impactos Ambientais Da Ocupação Irregular Na Área De Preservação Permanente (APP) Do Córrego Tamanduá Em Aparecida De Goiânia. In: Congresso Brasileiro de Gestão Ambiental. 2. 2011. Goiás. Anais eletrônicos [...]. Aparecida de Goiânia. http://www.ibeas.org.br/congresso/Trabalhos2011/VI-009.pdf

Santos, A. N. (2009). Interferência Da Poluição Visual na Percepção do Centro Tradicional da Cidade de Salvador: Do Forte de São Pedro A Praça Castro Alves. [Dissertação]. Salvador. Universidade Federal da Bahia Escola Politécnica. http://www.ppec.ufba.br/site/publicacoes/interferencia-da-poluicao-visualna-percepcao-do-centro-tradicional-da-cidade-de-salvador.

Santos, R. \& Cavalheiro Neto, A. (2009). A importância do paisagismo quanto a promoção de qualidade de vida. Trabalho de Conclusão de Curso. Faculdade Assis Gurgacz, [Trabalho de Conclusão de Curso]. Paraná. https://www.fag.edu.br/upload/graduacao/tcc/522a518a0a3fd.pdf.

Silva, A. F. C., Costa, M. S. S., Botelho, m. g. 1., Furtado, L. G., Batista, V. A., Carneiro, C. R. O., Morales, G. P. (2020). Impactos das alterações no uso e cobertura do solo no município de Altamira, Pará. Research Society and Development, 9(8), e303985488. http://10.33448/rsd-v9i.5488

Silva, g. c., Lucas, F. C. A. (2019). Ribeirinhos e a hidrelétrica de Belo Monte: a desterritorialização e influências no cultivo de plantas alimentícias. Ambiente \& Sociedade, 22, $\mathrm{e} 02961$.

Silva, P. R. F., \& Oliveira, R. S. (Org.) (2008). Roraima 20 anos as geografias de um novo estado. EduUFRR.

Souza, Q. P. S., Souza, P. T. S., Freitas, A. D. D., Paraense, V. C., \& Silva, S. A. S. Diagnóstico quali-quantitativo da arborização das praças do município de Altamira, Pará. Enciclopédia Biosfera, 9(17), 1080,1089.

Teixeira, A. W. F. (2016). Proposta de revitalização de áreas degradadas: estudo de caso da Lagoa Pirapitinga. Revista Online IPOG Especialize, 1(11),1-20.

Vargas, H. L. (2008). Ocupação Irregular De APP Urbana: Um Estudo Da Percepção Social Acerca Do Conflito De Interesses Que Se Estabelece Na Lagoa Do Prato Raso, Em Feira De Santana, Bahia. Sitientibus, (39),7-36.

Vieira, A. S., Moraes, L. A., Lima, A. S., Santos, L. A. Batista, W. F. M. (2020). Parque Estação Cidadania, Teresina, Piauí, Brasil: processo de criação, implantação e evolução temporal de paisagem. Research. Society and Development, 9(8), e86984814. 